\title{
Fast and ultrafast Kelvin wave modulations of the equatorial evening $F$ region vertical drift and spread $\mathrm{F}$ development
}

\author{
Mangalathayil A Abdu*, Christiano GM Brum², Paulo P Batista', Subramanian Gurubaran³, Dora Pancheva4, \\ Jose V Bageston ${ }^{1}$, Inez S Batista ${ }^{1}$ and Hisao Takahashi ${ }^{1}$
}

\begin{abstract}
In this paper, we investigate the role of eastward and upward propagating fast (FK) and ultrafast Kelvin (UFK) waves in the day-to-day variability of equatorial evening prereversal vertical drift and post sunset generation of spread F/plasma bubble irregularities. Meteor wind data from Cariri and Cachoeira Paulista (Brazil) and medium frequency (MF) radar wind data from Tirunelveli (India) are analyzed together with Thermosphere-lonosphere-Mesosphere Energetics and Dynamics/Sounding of the Atmosphere using Broadband Emission Radiometry (TIMED/SABER) temperature in the 40- to 100-km region to characterize the zonal and vertical propagations of these waves. Also analyzed are the $F$ region evening vertical drift and spread F (ESF) development features as diagnosed by Digisonde (Lowell Digisonde International, LLC, Lowell, MA, USA) operated at Fortaleza and Sao Luis in Brazil. The SABER temperature data permitted determination of the upward propagation characteristics of the FK (E1) waves with propagation speed in the range of $4 \mathrm{~km} /$ day. The radar mesosphere and lower thermosphere (MLT) winds in the widely separated longitude sectors have yielded the eastward phase velocity of both the FK and UFK waves. The vertical propagation of these waves cause strong oscillation in the $\mathrm{F}$ region evening prereversal vertical drift, observed for the first time at both FK and UFK periodicities. A delay of a few (approximately 10) days is observed in the $F$ region vertical drift perturbation with respect to the corresponding FK/UFK zonal wind oscillations, or temperature oscillations in the MLT region, which has permitted a direct identification of the sunset electrodynamic coupling process as being responsible for the generation of the FK/UFK-induced vertical drift oscillation. The vertical drift oscillations are found to cause significant modulation in the spread F/plasma bubble irregularity development. The overall results highlight the role of FKUUFK waves in the day-to-day variability of the ESF in its occurrence season.
\end{abstract}

\section{Background}

Plasma structuring of the equatorial nighttime ionosphere, a.k.a, equatorial spread F (ESF) irregularities, is known to suffer large degree of spatial and temporal variabilities of wide-ranging scales due to external forcing. Their impacts on the space systems are well known, while their implication to the underlying interactive processes in the atmosphere-ionosphere system is a subject of active investigation. Besides any overhead forcing from space weather disturbances, the equatorial ionosphere can be subjected to variability arising from vertical coupling process driven

\footnotetext{
* Correspondence: ma.abdu@inpe.br

${ }^{1}$ Instituto Nacional de Pesquisas Espaciais (INPE), Sao Jose dos Campos 12227-010, Brazil

Full list of author information is available at the end of the article
}

by upward propagating atmospheric waves originating from their tropospheric/stratospheric sources. Planetary waves of various periodicities, in 2- to 20-day range, are now known to modulate the key parameters of the equatorial ionosphere, the layer height, electric fields, layer critical frequencies, Es layer formation, etc. (Forbes and Leveroni 1992; Pancheva et al. 2003; Haldoupis et al. 2004; Takahashi et al. 2005; Abdu et al. 2006a, etc.). Planetary wave $(\mathrm{PW})$ signatures have also been found in ionospheric total electron content (Chang et al. 2011) and $S_{4}$ scintillation indices (Liu et al. 2013).

The nature of the waves and that of the associated vertical coupling processes have been investigated by studying the characteristics of the upward propagating waves at different height domains, especially in the mesosphere 
and lower thermosphere (MLT) region and at ionospheric heights. Measurements of the mesospheric and lower thermospheric wind fields (the zonal and meridional components) have proved to be powerful tools in the diagnostics of the wave characteristics at these height regions. An important feature of PWs is that they occur in episodic nature so that attention needs to be focused on specific intervals. For example, a study of the 2-day waves in mesospheric zonal and meridional winds by medium frequency (MF) radar over Adelaide by Harris (1994) showed their occurrences for 2- to 3-week duration generally following mid-summer. Also from the MF radar over Tirunelveli, Gurubaran et al. (2001) found quasi 2-day waves dominated by meridional winds occurring during December to January months. Lima et al. (2004) found that the quasi 2-day waves are dominated by meridional winds at Cachoeira Paulista occurring from December to February, while at Cariri, Lima et al. (2007) found that the waves occur in December to February with the same characteristics as those observed at Cachoeira Paulista, but also in June to July. From meteor radar wind measurement over Ascension Island, Pancheva et al. (2004) found the overall wind characteristics to be in agreement with those of other equatorial longitudes, and the zonal wind was dominated by 3- to 7-day waves while the meridional wind component by quasi 2-day waves around southern summer months. The manifestations of these waves at ionospheric heights are by now well established in the form of the associated oscillations in the F layer critical frequencies (Chen 1992; Forbes and Leveroni 1992), sporadic E layer top frequencies (Pancheva et al. 2003), nighttime F layer heights, and evening prereversal vertical drift and ESF (Abdu et al. 2006a, b; Takahashi et al. 2005, 2006; Fagundes et al. 2009). Since the PW's penetration all the way to ionospheric $\mathrm{F}$ region heights is uncertain, their observed signatures at these heights are widely believed to arise from their modulation of the tidal wind modes (that are active in the dynamo region) by nonlinear interaction (Pancheva et al. 2003; Haldoupis et al. 2004).

Kelvin waves are one of the PW types trapped in the equatorial and low-latitude region where the Coriolis force is negligible. They are eastward propagating waves and have predominance of the kinetic energy in the zonal wind component. Kelvin waves are also present in temperatures, which constitute the potential energy of the wave. There are three categories of Kelvin waves, identified from their distinct periodicities, vertical wavelengths, and propagation characteristics which are classified as follows: slow (approximately 16 days), fast (6 to 7 days), and ultrafast (3 to 4 days) waves. The ultrafast Kelvin waves (UFK) first reported by Salby et al. (1984) have the longest vertical wavelength $(>50 \mathrm{~km})$ and therefore can penetrate to higher heights to the mesosphere and to the ionospheric dynamo regions (above $100 \mathrm{~km}$ ), as was first pointed out by Forbes (2000) from a globalscale wave model (GSWM) simulation study. The manifestation of these waves at mesospheric heights was first identified by Vincent (1993). This and later works that followed have identified the wave characteristics, in terms of their periods and vertical waves length, as ranging from 3 to 4 days and varying from 40 to $88 \mathrm{~km}$, respectively, (for example, Riggin et al. 1997; Kovalam et al. 1999; Sridharan et al. 2002; Lima et al. 2008). A simulation study on vertical propagation of the fast and ultrafast Kelvin waves using the Kyushu GCM by Chen and Miyahara (2012) showed that in the course of upward propagation, from the source of their generation in the troposphere, the shorter period waves dominated with increasing height. A similar study using Aura MLS observational data was performed by Davis et al. (2012), who found that the fast Kelvin (FK) waves, on average, dominate mainly below $80 \mathrm{~km}$. Thus, while the UFK waves penetrated to approximately $105 \mathrm{~km}$, the FK waves reached well below $100 \mathrm{~km}$. The study also confirmed the dominance of zonal wind velocities at equatorial and low latitudes with insignificant meridional winds, besides other relevant characteristics of these waves.

In this paper, we present results showing some characteristics of these waves based on observations at widely separated longitudes (Brazil and India) as well as their upward propagation leading to modulation of the F region evening plasma vertical drift, that is, the prereversal enhancement in the vertical drift (PRE)/zonal electric field, and to spread F plasma bubble irregularity development. The data analyzed is described in the 'Methods' section. Important aspects of the height and longitudinal characteristics of these waves and their modification of the $\mathrm{F}$ region evening vertical drift and ESF are discussed in the 'Results' section. The results are further discussed and interpreted in the 'Discussion' section, and the 'Conclusions' section presents the summary and conclusions.

\section{Methods}

In this study, we have analyzed mesospheric winds from equatorial and low-latitude locations in Brazil and India, $\mathrm{F}$ region evening vertical drift velocity and spread F data from Brazil, and Thermosphere-Ionosphere-Mesosphere Energetics and Dynamics/Sounding of the Atmosphere using Broadband Emission Radiometry (TIMED/SABER) temperature data at stratospheric and mesospheric heights during the period from 1 August and 31 October 2005.

The zonal and meridional components of the mesospheric winds are analyzed using their hourly averaged values in the height region from 88 to $98 \mathrm{~km}$ at 2-km height resolution. The locations of the stations are shown in Figure 1. The wind data from Tirunelveli $\left(8.7^{\circ} \mathrm{N}, 77.8^{\circ} \mathrm{E}\right)$ were acquired by an MF radar (Vincent and Lesicar 1991; 




Figure 1 Map showing the locations of stations from where the data are analyzed in this paper.

Gurubaran et al. 2001) operated in spaced antenna mode. The winds over Cariri $\left(7.4^{\circ} \mathrm{S}, 36.5^{\circ} \mathrm{W}\right)$ and Cachoeira Paulista $\left(22.6^{\circ} \mathrm{S}, 45^{\circ} \mathrm{W}\right)$ were measured by a SKiYMET meteor radar (Hocking et al. 2001) operated at $30.24 \mathrm{MHz}$.

Digisonde (Lowell Digisonde International, LLC, Lowell, MA, USA) data from Fortaleza $\left(3.9^{\circ} \mathrm{S}, 38.4^{\circ} \mathrm{W}\right)$ and Sao Luis $\left(2.33^{\circ} \mathrm{S}, 44.2^{\circ} \mathrm{W}\right)$ were used to obtain the $\mathrm{F}$ layer evening vertical drift calculated from the true height $h(f)$ values, as $d h(f) / d t$. The drift velocity thus obtained is a reliable measure of the vertical plasma drift in the evening hours when the $\mathrm{F}$ layer rises to above approximately $300 \mathrm{~km}$ due to the PRE. The spread F intensity is quantified in terms of the parameter fop (the top frequency of the range spread $\mathrm{F}$ trace) that was read from each ionogram (Abdu et al. 2012).

The SABER/TIMED temperature measurements are made over the globe from lower stratosphere to lower thermosphere (20 to $120 \mathrm{~km}$ ). The continuous measurements are available only in the latitude range from $50^{\circ} \mathrm{S}$ to $50^{\circ} \mathrm{N}$. The presented results are derived from the Version 1.07 of the SABER data, which were downloaded from the website http://saber.gats-inc.com. The data are averaged into $5-\mathrm{km}$ altitude and $10^{\circ}$ latitude bins, and each bin is independently analyzed. We work in universal time (UT), and for each altitude and latitude, the data were arranged in a matrix with 24 columns (this is the longitude with a step of $15^{\circ}$ ) and the number of rows is equal to the length of the considered period of time in hours. The method for deriving the daily characteristics of the atmospheric waves from the SABER temperature data is described by Pancheva et al. (2009). In order to extract the waves from the SABER data (i.e., to determine their amplitudes and phases) at a given latitude and altitude, we perform a linear twodimensional (time-longitude) least squares fitting for the mean temperature, the first three tidal periods (diurnal, semidiurnal, and terdiurnal tides) with zonal wave numbers up to 4 , the first four modes of the stationary planetary waves (SPWs) (i.e., SPWs with zonal wave numbers 1, 2, 3, and 4), and the zonally propagating planetary waves with the following periods: $5.5,10,16$, and 23 days with zonal wave numbers up to 3 . All these components are extracted simultaneously from the temperature data. Because it takes SABER 60 days to sample $24 \mathrm{~h}$ in local time by combining ascending and descending data together, the length of the sliding window used for performing the least squares fitting procedure is 60 days. Then the 60-day window is moved through the time series with steps of 1 day in order to obtain the daily values of the wave characteristics.

\section{Results}

Height and longitude characteristics of the Kelvin waves

Figure 2 upper panel shows the latitude structure of the spectral amplitude of the 5.5-day Kelvin (E1) wave in temperature (in $\mathrm{K}^{\circ}$ ) at $90 \mathrm{~km}$ as obtained from the TIMED/SABER data for the period from 1 August to 31 October 2005. The height structure over the equator of the same spectral amplitude is shown in the lower panel. The wave activity already present in the beginning of August showed a break and reinitiated in the latter half of August and continued well to the end of October and was modulated by oscillations with periods of a few days. The wave activity is clearly restricted to the vicinity of equatorial latitude as can be noted in the upper panel. Wave amplification with increasing height is evident in the lower panel. It may be noticed that the amplitude at $90 \mathrm{~km}$ is larger by a factor of 3 as compared to its values at $40 \mathrm{~km}$. Such increase of wave amplitude is a wellknown characteristic of an upward propagating Kelvin wave (Pancheva et al. 2004). It may be noted further that there are layer structures in the wave amplification above approximately $40 \mathrm{~km}$ with more intensity above approximately $75 \mathrm{~km}$, the majority of them have spacing of around $10 \mathrm{~km}$ or more. Usually, the vertical amplitude structure of the approximately 5.5-day E1 Kelvin wave 

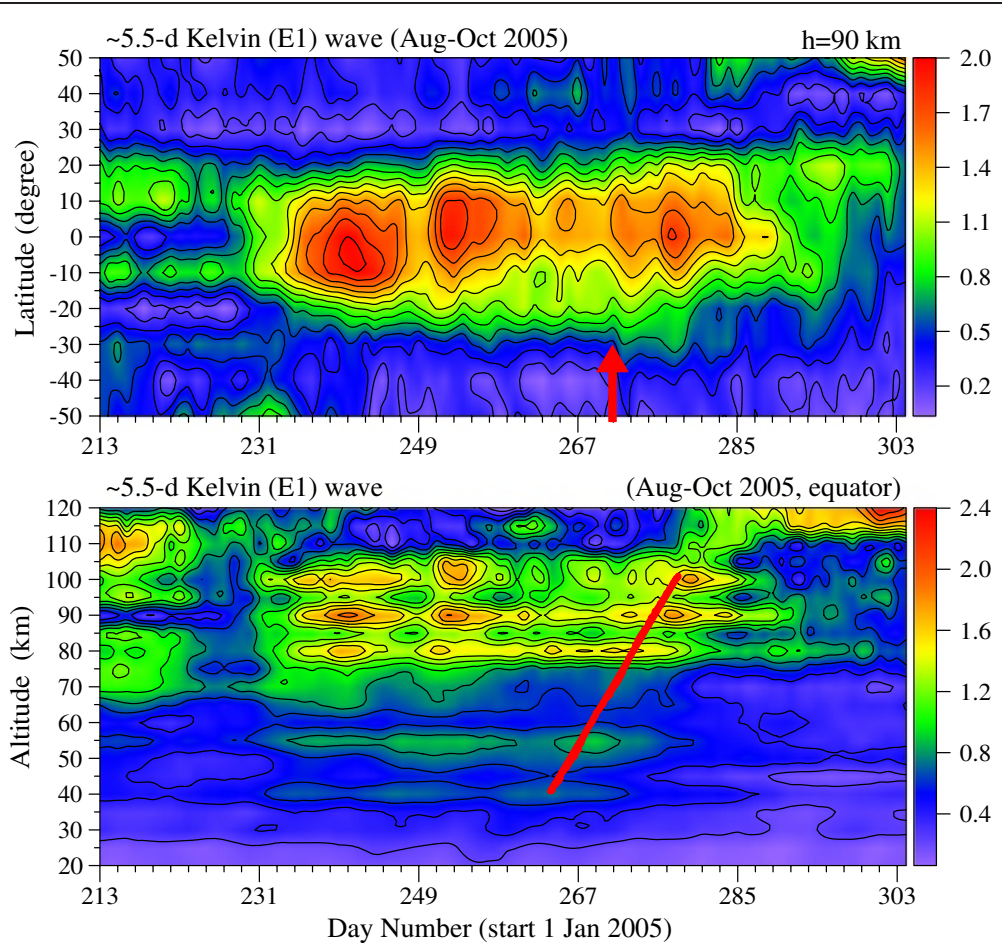

Figure 2 Latitude and height structures of the approximately 5.5-day Kelvin (E1) wave amplitude (in K). The wave characteristics as seen in the SABER temperature during 01 August to 31 October 2005 are plotted. The latitude structure at $90 \mathrm{~km}$ is shown in the upper panel and the height structure of the same wave over the equator is shown in the lower panel. Upward propagation of the wave amplification from $40 \mathrm{~km}$ to approximately $100 \mathrm{~km}$ is indicated by a slant line.

indicates multi-peaked maxima that are particularly well evident in summer. Such multi-peaked vertical structure can be distinguished even in the averaged (2002 to 2007) wave amplitudes as in this case (Pancheva et al. 2010). This interesting feature has not yet been studied but could be related to the presence of inversion layers or wave-wave coupling processes.

Another point to be noted is the decay of the wave activity that started at $40 \mathrm{~km}$ in the beginning of October, which is significantly earlier than in the height region of 90 to $100 \mathrm{~km}$, where the activity continued until late in October. In general, there is clearly a longer persistence of the wave activity at higher heights, which can be caused by a time delay due to the upward propagation of the waves. A vertical arrow in Figure 2, upper panel (on day 271) indicates the initiation of an amplification process at $90 \mathrm{~km}$ that appears to have originated at $40 \mathrm{~km}$ near day 258. In the lower panel, a slant line starting at approximately $40 \mathrm{~km}$ indicates the upward amplification process. It may be pointed out that the characteristics of the vertical propagation from near $40 \mathrm{~km}$ until around $90 \mathrm{~km}$ is more evident towards the end of the event episode as indicated by the upward slant line. An estimate of the upward propagation velocity yields a value in the range of approximately $4 \mathrm{~km} /$ day. From the phase plot (not shown here), the vertical wavelength is found to be about $20 \mathrm{~km}$ which yields a vertical velocity of 3.7 to $4 \mathrm{~km} /$ day. From the analysis of the SABER data for upward propagation of UFK waves, Takahashi et al. (2007) found that these waves propagate vertically from the lower stratosphere to the lower thermosphere with a group velocity of $5 \mathrm{~km} /$ day. The upward propagation velocity of the FK wave in the present case is found to be slower than that. These characteristics will be invoked later in the discussion of our overall results that cover height regions extending to the ionosphere dynamo and to the $\mathrm{F}$ layer heights where vertical drift oscillations in response to both the FK and UFK waves were observed.

Continuous wavelet transform was applied on the hourly averaged values of the winds from MF radar and meteor radars, and their respective power spectra were obtained by using Morlet mother function. Figure 3 presents the wavelet power spectra of the zonal and meridional winds from MF radar over Tirunelveli from day 213 (1 August) until day 304 (31 October) of 2005 at six heights between 88 and $98 \mathrm{~km}$. Similar results for meteor radar wind over Cariri and Cachoeira Paulista are shown in Figures 4 and 5, respectively. There are a number of spectral peaks at different periods spread over the entire observational interval in the three figures. A comparison shows that there is some degree of similarity between the Cariri zonal wind and SABER temperature 


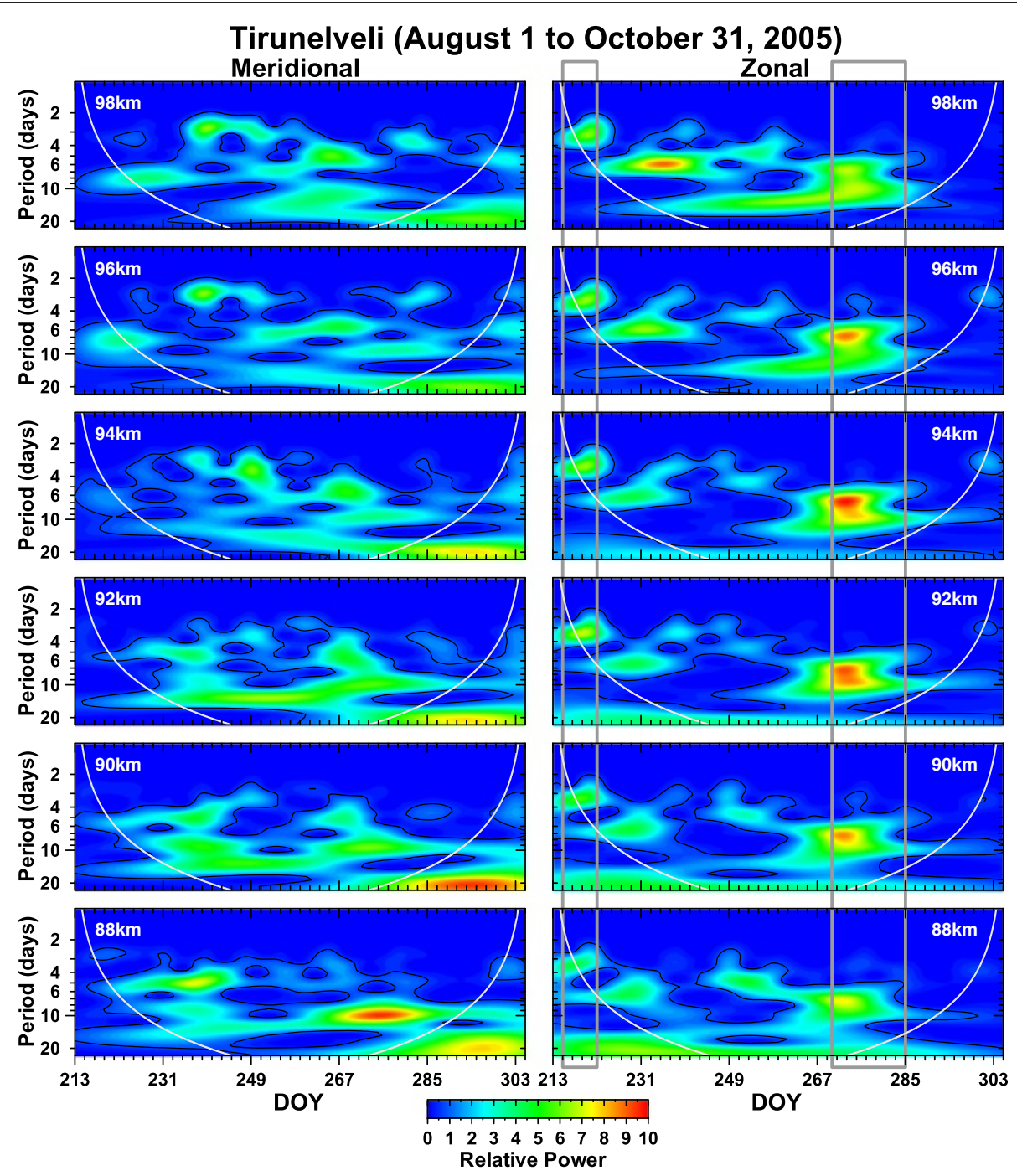

Figure 3 Wavelet power spectra of the zonal and meridional components of the MLT winds over Tirunelveli. The winds measured by an MF radar at Tirunelveli are plotted at 2-km height interval from $88 \mathrm{~km}$ up to $98 \mathrm{~km}$. Hourly averaged values were used in the analysis. The black contour lines in the power spectrum (feebly visible) denote the regions with a $95 \%$ confidence level, and the white thicker lines represent the cone of influence (COI), defined as the region of the wavelet spectrum where edge effects become important (at the beginning and end of the data series). The scale of the power spectrum, presented as relative power, after normalizing to 10 units as the highest value, is shown at the bottom.

spectra especially with respect to the 5-day wave amplification during days 229 to 260 seen in the SABER spectra, which is strong between 80 and $105 \mathrm{~km}$. The wave amplification seen in the SABER temperature near $80 \mathrm{~km}$ around day 270 appears to be comparable to the beginning of wave amplification in the zonal wind over Cariri around the same day. The amplification after day 270 is not seen in the zonal wind below $94 \mathrm{~km}$ but clearly seen above this height. (The similarity is relatively less conspicuous in the case of Tirunelveli.) We may note that there are some common spectral peaks in the zonal wind consistently present at all the three sites, as can be verified from Figures 3, 4, and 5 that are highlighted by vertical rectangle. The approximate specifications of the wave periods and day intervals are listed in Table 1. The two highlighted intervals identified as interval- 1 and interval-2 cover approximately the day interval 215 to 222 (beginning of August) and days 270 to 285 (end of September to middle of October), respectively. We shall be concerned with these two spectral peaks, but mainly focusing on the latter interval. It is important to note that during these intervals, the oscillations are confined to the zonal wind component only, with no oscillation present in the meridional component, a feature consistently evident in all the three sites. It may be noted that the wave disturbances of interval-2 starts a few days earlier over Tirunelveli, with respect to the highlighted 270- to 285-day window than over Cariri where the disturbance window is made to 


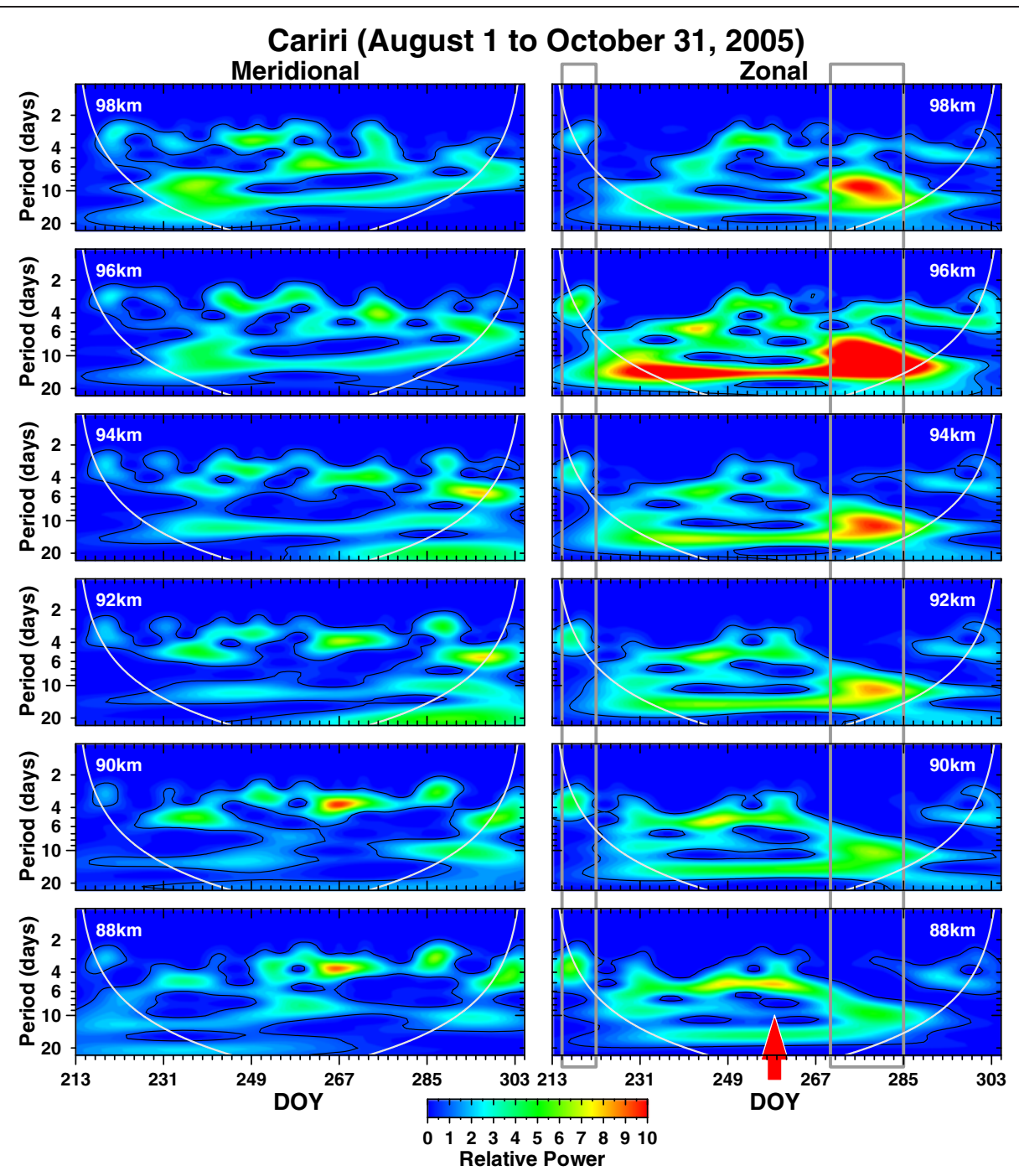

Figure 4 Wavelet power spectra of the zonal and meridional components of the MLT winds over Cariri. The winds measured by a SKiYMET radar at Cariri are plotted at 2-km interval from $88 \mathrm{~km}$ up to $98 \mathrm{~km}$. Hourly averaged values were used in the analysis. All other specifications are the same as for Figure 3.

nearly match with that of the highlighted interval. Although spectral peaks in zonal wind are present at Cachoeira Paulista (Figure 5), their absolute amplitudes are significantly smaller than they are at Tirunelveli and Cariri, an expected feature of the Kelvin waves since this station is located farther away from the equator. Further, the degree to which the oscillations in the meridional wind are weaker than in the zonal wind is much stronger over Cachoeira Paulista than it is at the other (equatorial) stations. Such features attest to the fact that these oscillations are indeed manifestations of eastward and upward propagating Kelvin wave episodes.

During interval-1, clear spectral peaks of approximately 3-day period are present at all heights, which can be characterized as a UFK episode. It is interesting to note that the 5-day Kelvin (E1) wave is present during the same period at heights above $70 \mathrm{~km}$ in Figure 2. Interval-2, which is of our major focus here, presents zonal wind oscillations that persisted for longer durations at all the three sites. The oscillation periods are characteristic of the dominance of FK waves of around 5- to 6-day periods but spread around to lower and higher periods. Especially during interval-2, there appears to be evidence on dominance of periods around 10 days in the MLT region as can be noted over Tirunelveli. The presence of UFK wave that got amplified toward higher heights (as the results at $\mathrm{F}$ layer heights, to be discussed later, show) appears much weaker in these spectral regions that are dominated by the FK waves.

As an important feature, we note that in interval- 1 and interval-2, there is a time lag in the occurrence of the spectral peaks over Cariri in relation to their occurrence 


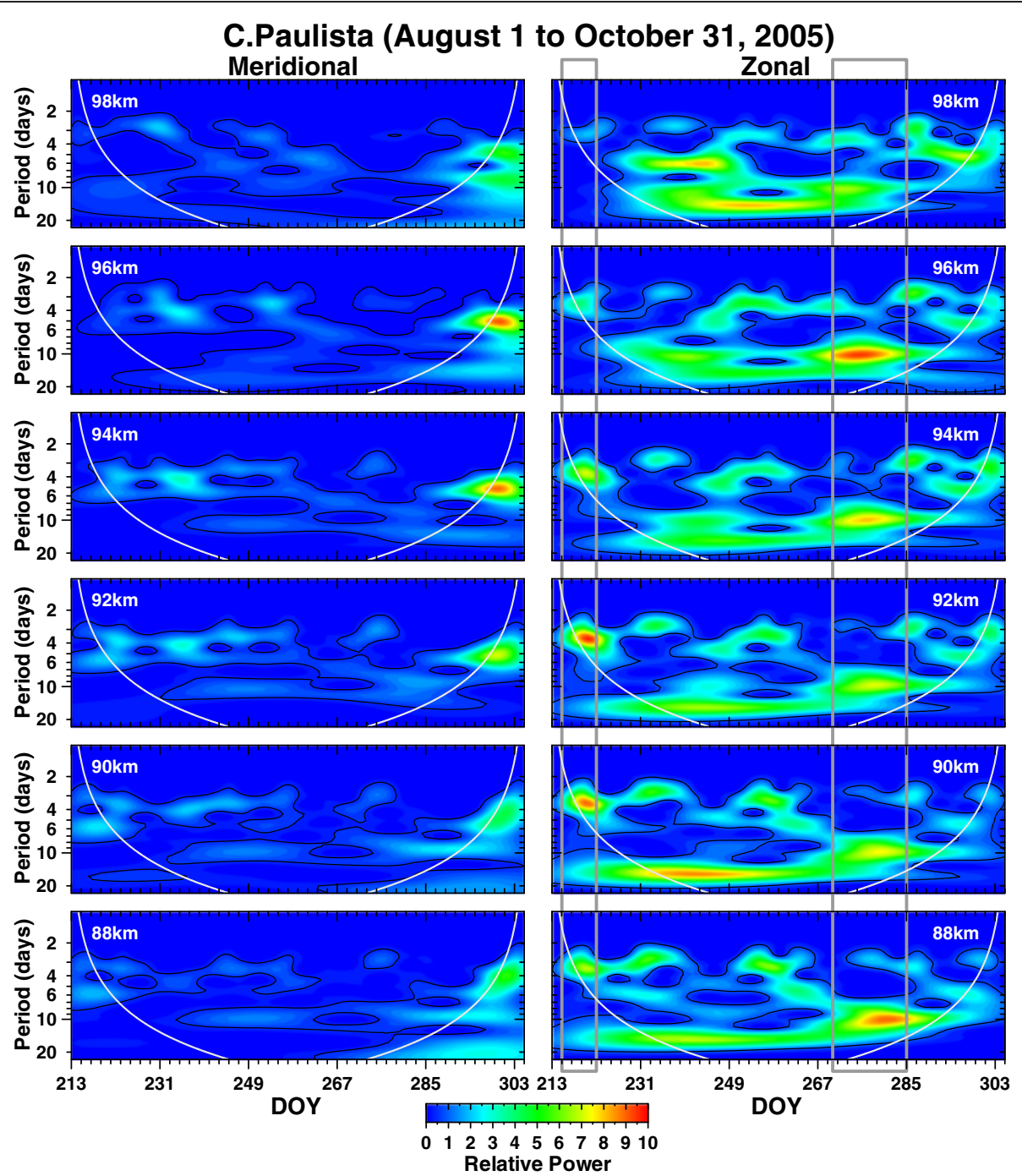

Figure 5 Wavelet power spectra of the MLT zonal and meridional winds over Cachoeira Paulista. The same plots as in Figure 4 but for the station Cachoeira Paulista.

over Tirunelveli, or vice versa. Figure 6A shows plots of decomposed 3- and 4-day UFK waves (of interval-1) for Cariri and Tirunelveli, in which we note phase propagating from the former to the latter site. The eastward phase velocity can be determined as approximately $120 \mathrm{~m} / \mathrm{s}$ which is compatible with the phase velocity for the UFK waves between Cariri and Ascension Island obtained by Takahashi et al. (2006) as $140( \pm 20) \mathrm{m} / \mathrm{s}$. The zonal wave number, $s=2 \pi R_{\mathrm{E}} \cos (\theta) / c \tau$ (where, $R_{\mathrm{E}}$ is the Earth radius, $\theta$ is the latitude, $c$ is phase velocity, and $\tau$ is the wave period), can be estimated as approximately 1 in this case. The decomposed 5- and 6-day wave amplitudes for the two sites are shown in Figure 6B. In this case, we note significant amplification of the oscillation amplitude in the height region from 88 to $98 \mathrm{~km}$, similar to that found in the SABER temperature field of FK waves between 40 and $90 \mathrm{~km}$, mentioned earlier. It can be noticed that the oscillations have phase propagating from Tirunelveli to Cariri

Table 1 Specifications of the wave oscillation of interest at the three radar sites

\begin{tabular}{lclllll}
\hline Sites & Interval-1 & & & Interval-2 & \\
\cline { 2 - 3 } & Dominant wave period (days) & Day intervals & & Dominant wave period (days) & Day intervals \\
\hline Tirunelveli & 3 to 4 & Day 214 to day 218 & & Approximately 3 to 12 & Day 263 to day 285 \\
Cariri & 3 to 4 & Day 213 to day 216 & & Approximately 3 to 12 & Day 269 to day 291 \\
Cachoeira Paulista & 3 to 4 & Day 214 to day 218 & & Approximately 3 to 12 & Day 267 to day 287 \\
\hline
\end{tabular}






presenting a delay of approximately 3 days, which corresponds to an eastward phase velocity of approximately $100 \mathrm{~m} / \mathrm{s}$. In this case also, the zonal wave number $\mathrm{s}$ is reasonably close to 1 . A westward propagation driven by a strong westward background wind appears unlikely here considering the large longitudinal separation of the two stations. Further, we do not have data to verify such an unlikely possibility. In this context, it may be noted that while the eastward phase velocity reported in the literature for UFK waves are in the range of 120 to $160 \mathrm{~m} / \mathrm{s}$ (Salby et al. 1984; Forbes 2000; Takahashi et al. 2007), the FK waves have been reported to have eastward phase velocity of 50 to $80 \mathrm{~m} / \mathrm{s}$ (Hirota 1978).

\section{Kelvin wave modification of vertical drift and ESF}

The $F$ region evening prereversal vertical drift and post sunset spread F occurrence were analyzed over Fortaleza and Sao Luis during the August-October period, specifically looking for any signature due to the Kelvin wave activity. Figure 7 shows the wavelet power spectra of the prereversal vertical drift velocity peak (Vzp) over Fortaleza and Sao Luis as a function of the day of the year. (There is no data over Sao Luis during the days 214 to 264.) We note in the upper two panels strong spectral peak in the vertical drift (Vzp) around a 3-day period at both Fortaleza and Sao Luis, which is a clear manifestation of a dominating UFK wave that started near day 280 . The amplification of this UFK wave with increase in height has occurred in a manner consistent with the occurrence of FK wave amplification at $90 \mathrm{~km}$ on day 271, indicated by an arrow in Figure 2. Spectral peak of UFK wave of weaker strength is present over Fortaleza also during interval-1 with corresponding FK wave amplification in Figure 2. In order to check the presence of FK wave signature in the $\mathrm{F}$ region for the interval-2 episode (which is of our primary focus), we recalculated the power spectra after smoothing out the 3 -day period, with results plotted in the two lower panels. Here, the presence of 5-day period is clearly evident, thereby demonstrating that the vertical drift oscillations over Fortaleza and Sao Luis, during interval-2, are driven by a broader wave spectrum that includes UFK as well as FK waves. We may point out that the similar spectral peaks simultaneously observed at both locations are a strong supporting evidence of the presence of UFK/FK wave effects.

The effect of these vertical drift oscillations on the intensity and initiation time of the spread F occurrence is demonstrated in Figure 8 that shows (in the upper panel) the SF intensity over Fortaleza as a function of UT (LT $+3 \mathrm{~h}$ ) and the day of the year. Here, the spread $\mathrm{F}$ intensity is represented by the parameter fop (the top frequency of a range spreading $\mathrm{F}$ layer trace). A recent study by Abdu et al. (2012) showed that the parameter fop is a convenient and dependable parameter to quantify the SF intensity. Further, a statistical study by Uma et al. (2012) has shown that the SF intensity local time-seasonal variation as represented in the International Reference Ionosphere (IRI) Model (Bilitza and Reinisch 2008) is comparable to the scintillation $S_{4}$ index variation as observed by FORMOSAT/COSMIC during the solar minimum period (2007 to 2009) which they analyzed. The lower panel of Figure 8 presents the variation in the Vzp values over Fortaleza corresponding to the SF variation shown in the upper panel. In order to discuss the precise nature of the relationship 

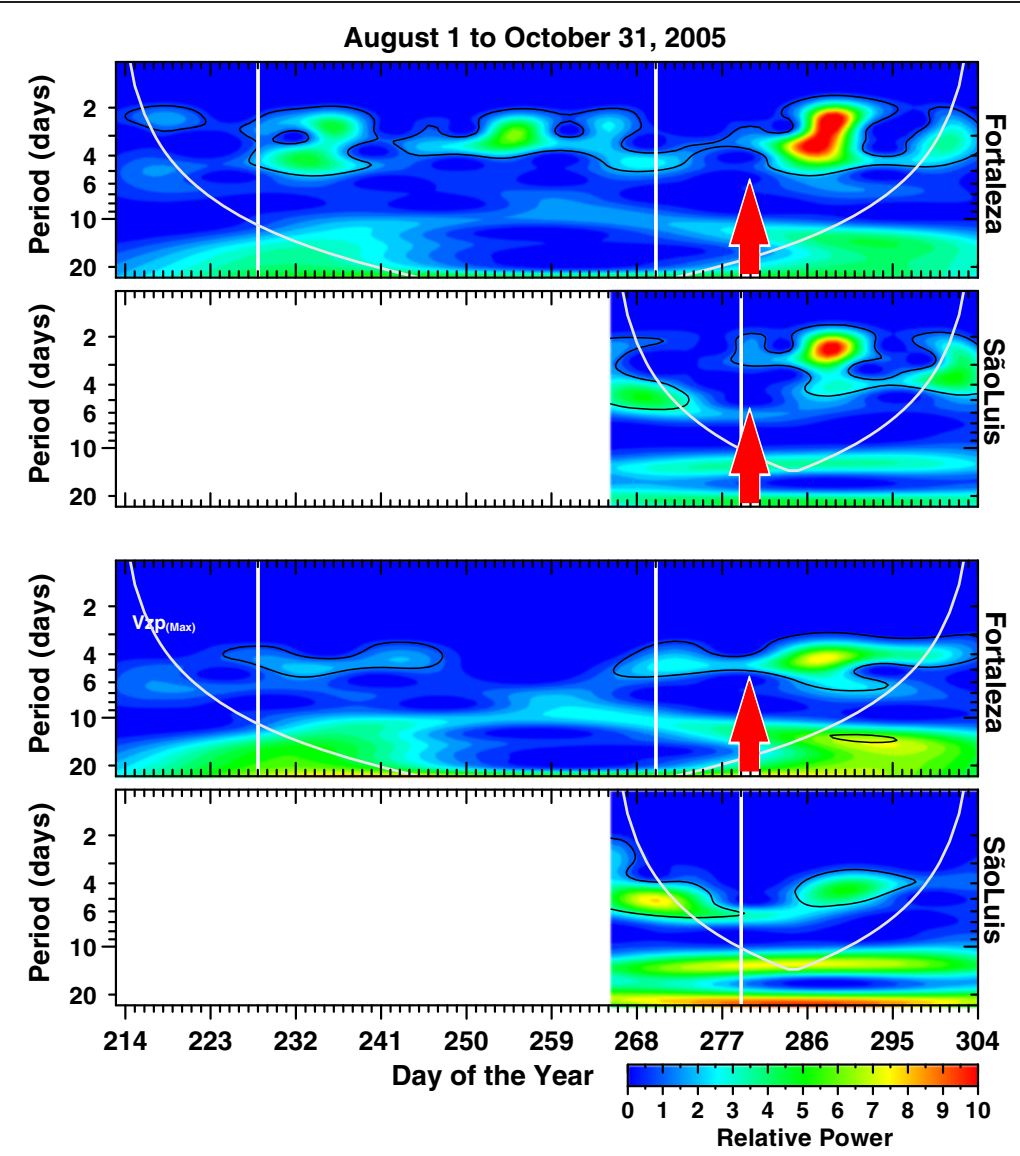

Figure $\mathbf{7}$ Wavelet spectra of the $\mathbf{F}$ region prereversal vertical drift velocity peak. The wavelet spectra of the $\mathrm{F}$ region prereversal vertical drift velocity peak, Vzp (near 18:30 LT), in which daily values (one value per day) are used. The top panel shows the power spectrum over Fortaleza, and the second (lower) panel shows the result for Sao Luis (600 km westward of Fortaleza). The lower two panels show the spectra obtained after applying a 3-day smoothing filter to the original daily values. Here, a longer period of around 5-day FK wave may be noted.

between the Vzp and ESF that is apparent in this figure, we need to take into account also the seasonal variation pattern of the ESF/plasma bubble irregularity occurrence in the Brazilian longitude sector. Over Brazil, the ESF occurrence has a broad seasonal maximum covering the months of September to March, with a broad minimum centered in the June months (see for example, Abdu et al. 1992). Thus, the period covered here is one of a transition from ESF nonoccurrence to ESF occurrence season. Similar seasonal pattern holds in general for the PRE intensity as well. Thus, until about middle of September (approximately day 260), the PRE intensity is weak, being below a threshold value required to initiate the instability process and therefore insufficient for SF development. Well into the ESF season, from the end of September and towards the end of October, there are clear cases of spread F development controlled by the PRE intensity. Of the numerous cases, the vertical arrows that are marked at the Vzp values indicate some. Besides the control on the SF intensity, the Vzp amplitudes appear to modulate also the local time of the SF initiation. Good examples can be noted on day 265 which clearly indicates an earlier start of the SF by approximately $30 \mathrm{~min}$ as compared to the neighboring days on either side. This was a UFK wave episode (as can be verified from Figure 7 over Fortaleza). The corresponding UFK activity in the zonal wind over Cariri can be noted peaking around day 260 (indicated by an arrow, but strong activity was present even from approximately day 250) in Figure 4 and a bit earlier over Tirunelveli (as can be noted in Figure 3). We may note that there are also cases of weak or delayed occurrence of SF that correspond to low values of the Vzp as indicated by the two horizontal bars centered around day 270 and day 298 (Figure 8).

We examined the possibility of any contribution to the observed PRE modulation arising from solar flux variations or magnetic disturbances. The wavelet power spectrum of the solar flux index, F10.7, shown in the top panel of Figure 9, clearly rules out any such contribution from the solar flux variation. To examine any possible contribution from magnetic disturbances, we used the auroral activity index (AE) known to be a key parameter (perhaps the most relevant one) that can modify the PRE 




Figure 8 The local time versus day plot of ESF intensity, and the prereversal drift amplitude. The upper panel shows the local time versus day plot of the spread F (SF) intensity over Fortaleza. The SF intensity is quantified in terms of the parameter fop, the top frequency of the range spread $F$ trace. The lower panel shows the amplitude of the prereversal vertical drift velocity peak, Vzp, that occurs near 21:00 UT (18:00 LT). The values near 20:50 UT/17:50 LT are also shown for comparison.



Figure 9 Wavelet power spectra of the solar flux F10.7 and auroral activity indices. The top panel shows the wavelet spectrum of F10.7 index. The middle panel shows the wavelet spectrum of the AE averages during 15 to $18 \mathrm{LT}$ just prior to the PRE peak drift velocity (one value per day) to verify possible influence of prompt penetration electric fields on the PRE. The bottom panel shows the corresponding results for the daily average AE values to verify any possible influence of disturbance dynamo electric field on the PRE vertical drift. 
vertical drift through disturbance electric field (see, for example, Abdu et al. 2009). Two types of storm time electric fields are considered: (1) the prompt penetration electric field that occurs during a sub-storm development and short-term recovery phases (e.g. Kikuchi et al. 2008) and (2) the disturbance dynamo electric field that occurs during recovery phase of a storm (Fejer et al. 2008). The $\mathrm{AE}$ averages during the hours 15 to $18 \mathrm{LT}\left(\mathrm{AE}_{15-18 \mathrm{LT}}\right)$ that immediately precedes the PRE were used to examine the occurrence of the type 1 (prompt penetration) electric field and the daily average $\mathrm{AE}$ values $\left(\mathrm{AE}_{\text {ave }}\right)$ to examine the presence of the type 2 (disturbance dynamo) electric field. The lower two panels of Figure 9 show the wavelet periodograms of these AE averages. From previous studies, it has been noted that $\mathrm{AE}$ variations less than around $500 \mathrm{nT}$ of amplitude do not produce any significant effect on the PRE vertical drift (Abdu et al. 2009). Of the two intervals of the vertical drift episode that were specified before ('Height and longitude characteristics of the Kelvin waves' section), we note that for interval-1, spectral peaks in both the $\mathrm{AE}$ indices occur somewhat displaced towards larger periods ( 3 to 4 days) than are the spectral peaks in the vertical drifts in Figure 7 (2 to 3 days). Further, the amplitudes of $\mathrm{AE}_{15-18 \mathrm{LT}}$ are relatively small, varying around 300 $\mathrm{nT}$, thus ruling out any influence from the penetration electric fields on the vertical drift oscillations for interval1. Any effect from disturbance dynamo electric field may also be ruled out based on the different period range, even though in this case the amplitude of $\mathrm{AE}_{\text {ave }}$ is higher. As regards interval-2 which is of our main focus in this paper, a careful examination of Figure 9 shows that neither $\mathrm{AE}_{15}$ 18LT nor $\mathrm{AE}_{\text {ave }}$ has any influence on vertical drift oscillation due to their weak amplitude and/or by their displaced periods and event days compared to those of the vertical drift. For example, the $\mathrm{AE}_{\text {ave }}$ spectrum near interval-2 in Figure 9 (bottom panel) peaks around day 283, whereas the spectral peak in the vertical drift for this interval peaks around day 288 in Figure 7. Thus, we may rule out any influence from variations in solar flux or magnetic activity in the PRE vertical drift oscillations of our main interest here.

Coming to the more spectacular case of interval-2 (which is our main focus), we note that the UFK and FK effects in the $\mathrm{F}$ region started on day 280 (indicated by an arrow in Figure 7). A few peaks in Vzp with corresponding SF intensification and earlier onsets can be clearly identified on days 285,288 , and 290. It is interesting to note that the UFK oscillations in the zonal wind over Cariri (that preceded this) had started around day 270, some 9 to 10 days earlier than the start of the wave activity in the vertical drift on approximately day 280 . Thus, a time delay of 9 to 10 days for the response at $\mathrm{F}$ region heights with respect to the UFK/FK waves in the MLT zonal wind is a consistent feature in these results.

\section{Discussion}

The results presented here clearly demonstrate the roles of upward propagating FK and UFK waves to cause significant modulation in the development of the equatorial evening prereversal enhancement in the plasma vertical drift/zonal electric field and in the consequent control of the ESF/plasma bubble irregularity growth. The results clearly demonstrate that these waves represent an important source of the day-to-day variability in the ESF occurrence. The vertical coupling processes underlying these cause-effect sequences have two distinct aspects: (1) upward propagation of the waves from the sources of their generation from equatorial tropospheric convective heating (e.g., Forbes 2000) to the MLT region involving wave amplification with increasing height, as seen in both the SABER temperature data and in mesospheric zonal wind, and (2) the response of the F region plasma as verified in the evening vertical drift oscillations and ESF irregularity development that involve electrodynamic coupling and plasma instability growth processes. For discussion purpose, we will identify them as aspect-1, or vertical coupling due to neutral dynamics (VCND), and aspect-2, or vertical coupling by electrodynamics (VCED).

As regards aspect-1, we have presented results demonstrating the global nature of the Kelvin waves connecting the wave features in widely separated Indian and Brazilian longitudes. The eastward phase propagation of the wave structure for the decomposed 5- and 6-day waves in the zonal wind yielded phase velocity that is compatible with such velocities previously cited in the literature. The UFK wave observed in the beginning of the period (interval-1) with 3- and 4-day periods was also compatible with the known UFK velocities. The amplification of these waves in their upward propagation up to approximately $100 \mathrm{~km}$ or above is an important factor that impacts on their ionospheric signatures that are of our primary focus here. We saw that the FK temperature wave increased in amplitude from $40 \mathrm{~km}$ to around $90 \mathrm{~km}$ by a factor of 3 . Corresponding wave amplification between 88 - and $98-\mathrm{km}$ height (the height limits of the radars) was noted in the zonal wind oscillation as well. Further, there is clear indication in the radar data that the UFK waves get amplified with increasing height. In this context, we note that Chen and Miyahara (2012) found from their Kyushu University CGM simulation that during the upward propagation of the Kelvin waves, their spectral peaks shifted towards shorter period with increase of height for periods shorter than approximately 10 days. They obtained prominent spectral peaks at 2.5 to 3.0 days for heights around $105 \mathrm{~km}$ and at 3.2 to 5.0 days in the range from 80 to $100 \mathrm{~km}$. Also, Miyoshi and Fujiwara (2006) showed in their general circulation model that the UFK wave could propagate upward from the troposphere to the lower thermosphere with a duration of 10 to 60 days. These 
results are in good agreement with the observational results presented here.

From the analysis of SABER data, Takahashi et al. (2007) determined the upward propagation velocity of UFK waves as approximately $5 \mathrm{~km} /$ day. In the present analysis, the upward velocity of the FK waves is found to be in the region of $4 \mathrm{~km} /$ day. The consideration of this upward velocity is a critical factor in our interpretation of the possible mechanism responsible for the observed UFK/FK wave response by the F region, as will be discussed below.

An important point, concerning the VCED, is the delay in the occurrence of the $\mathrm{F}$ region vertical drift oscillation of interval-2 that starts around day 280 (Figure 7) with respect to the UFK/FK oscillations in the zonal wind that start around day 270 over Cariri (Figure 2). The delay is of the order of 10 days. Similar value for the delay results also if we use the days of the peak activities as reference. Considering the $\mathrm{F}$ region height at which vertical drift occurs to be around $350 \mathrm{~km}$ and the vertical propagation of the UFK/FK waves to be at a rate of $5 \mathrm{~km} /$ day (as mentioned before), the delay required for the waves to propagate to the F region heights and produce the vertical drift oscillations by local interactive process should be of the order of 50 days. This value far exceeds the observed delay, which is of the order of 10 days. On the other hand, if we consider that the UFK/FK waves reaching the dynamo region, around 120 to $140 \mathrm{~km}$, could be responsible for modifying the vertical drift through electrodynamic coupling process, it appears that the delay can be accounted for if we adjust the observed vertical propagation velocity within acceptable limits. Thus, these results seem to totally exclude the possibility of the UFK/FK waves propagating up to the $\mathrm{F}$ region heights to modify the vertical drift by a local interactive mechanism.

We will briefly discuss below how the UFK/FK waves in the dynamo region can cause modulation of the post sunset $\mathrm{F}$ region vertical drift, the PRE. The well-established mechanism for the development of the evening PRE vertical drift/eastward electric field enhancement is based on the $\mathrm{E}$ and $\mathrm{F}$ layer sunset electrodynamic coupling involving the $\mathrm{F}$ layer dynamo. As explained by Abdu and Brum (2009), the thermospheric zonal wind that turns eastward near $17 \mathrm{LT}$ induces vertical electric field $\left(E_{z}\right)$ in the $\mathrm{F}$ region as represented by

$$
E_{z}=-U_{y} \times B_{0}\left[\Sigma_{\mathrm{F}} /\left(\Sigma_{\mathrm{F}}+\Sigma_{\mathrm{E}}\right)\right]
$$

where $U y$ is the thermospheric zonal wind, $B_{0}$ is the geomagnetic field intensity, and $\Sigma_{\mathrm{F}}$ and $\Sigma_{\mathrm{E}}$ are the integrated conductivities, respectively, of the $\mathrm{E}$ and $\mathrm{F}$ region segments of a field line. $B_{0}$ is the geomagnetic field intensity. On the dayside, the large value of $\sum_{\mathrm{E}}$ causes $E_{z}$ to remain small. At sunset, $\Sigma_{\mathrm{E}}$ decays into the nightside faster than $\Sigma_{\mathrm{F}}$ does, thus contributing to the increase of the vertical (downward) electric field towards the post sunset hours (that is, across the terminator). The application of curl-free condition to such an electric field leads to the zonal electric field enhancement (Rishbeth 1971), which is eastward on the dayside and westward on the nightside of the terminator, and is responsible for the PRE vertical drift. The PRE has been modeled by different approaches (see, for example, Heelis et al. 1974; Farley et al. 1986; Eccles 1998). The equatorial electrojet divergence at sunset also plays a role, but of secondary nature as was shown by Haerendel and Eccles (1992). It is also a wellknown fact that the development of the PRE is the most basic condition for the initiation of plasma instability process by Rayleigh-Taylor mechanism leading to generation of plasma bubble/spread F irregularities.

Basically, the two key parameters that control the PRE vertical drift amplitude and phase are (a) the thermospheric zonal wind and (b) the longitudinal/local time gradient in the E layer conductivity (Batista et al. 1986; Abdu et al. 2006b). We noted from the results presented in Figures 4 and 7 that the delay observed between the perturbations in the MLT zonal wind (of interval-2) and those in the $\mathrm{F}$ region vertical drift oscillation cannot be accounted for by the UFK/FK waves reaching $F$ layer heights in their upward propagation. Thus, we may rule out the possibility of UFK/FK wave modulation of the zonal wind at $\mathrm{F}$ region height as a possible mechanism for the observed drift oscillations. This leaves us with the possibility of the wave-induced modulation of the $\mathrm{E}$ region local time/longitude conductivity gradient as the only other mechanism capable of explaining the results.

The E layer conductivity longitudinal gradient, at sunset, can be modified significantly by the $\mathrm{E}$ layer zonal wind, as was shown by Abdu et al. (2003, 2006b). At the same time, the E layer conductivity longitudinal gradient exercises significant control on the amplitude and phase of the prereversal drift velocity, as was shown by Batista et al. (1986) and Abdu et al. (2004). Thus, we have the scenario of the $\mathrm{E}$ layer zonal wind controlling the E layer sunset conductivity gradient that it turn modulates the PRE vertical drift amplitude and phase. Detailed calculations have shown (e.g., Abdu et al. 2003) that an increasing westward wind could cause increase in the longitudinal/local time gradient in the post sunset $\mathrm{E}$ layer electron density and hence in the integrated conductivity. The effect of such an increase in the conductivity gradient is to raise the PRE vertical drift amplitude, as demonstrated, for example, by Abdu and Brum (2009). Conversely, an increase in eastward wind could produce a decrease in the conductivity longitudinal gradient with corresponding decrease in the PRE vertical drift. These model results cannot be precisely verified in the present set of observational data, however, 
because the measurements of the MLT zonal wind and the PRE vertical drift velocities refer to widely separated altitudes. Consideration based on extrapolation of the MLT zonal wind phase to the dynamo region presumed responsible for producing the observed PRE drift modulation, we feel, may not yield reliable results.

On the basis of the relationships just explained above, the planetary wave modulation of the PRE vertical drift that was observed by Abdu et al. (2006b) was interpreted as caused by the PW-induced oscillations in the $\mathrm{E}$ region zonal wind that in turn modified the longitudinal/local time gradient in the E layer integrated conductivity. This interpretation should hold also for vertical drift oscillation induced by a UFK wave through its modulation of the $\mathrm{E}$ region zonal wind. In a recent study, Onohara et al. (2013) used an E-F layer electrical coupling model (Heelis et al. 1974; Batista et al. 1986) in which the $\mathrm{E}$ layer tidal zonal winds and $\mathrm{F}$ layer dynamo electric fields produced the PRE vertical drift velocity. By superposing a UFK wave type oscillation on the E layer tidal wind, they obtained the $\mathrm{F}$ region evening vertical drift oscillation compatible with the drift oscillation observed due to the passage of a UFK wave. Thus, it looks that the PW/UFK/FK wave modification of the $\mathrm{E}$ layer winds through the resulting modification of the $\mathrm{E}$ layer conductivity local time gradient at sunset can indeed produce the corresponding oscillations in the prereversal vertical drifts as proposed by Abdu et al. (2006a), without the need to invoke the wave propagation up to $\mathrm{F}$ region altitudes.

The PRE modulation by the PW/UFK/FK waves has important consequence for the post sunset-pre midnight $\mathrm{F}$ layer heights and related parameters. The post sunset $\mathrm{F}$ layer height $(\mathrm{hF})$ variation, at a given plasma frequency, can be considered to follow the integrated values of the evening $\mathrm{Vz}$ (at that plasma frequency) and can be represented as $h F(t)=h_{0} F+\int V z d t$; here, $h_{0} F$ corresponds to a starting height at approximately $17 \mathrm{LT}$, which is just prior to the onset of the evening height enhancement. The effect of the PRE on the $h F$ diminishes towards later hours approaching midnight with almost no effect into the post midnight hours. In this context, it was shown by Abdu and Brum (2009) that while the PW oscillation in the PRE vertical drift was present also in the $h F$ values of the post sunset hours, it was totally absent in the $h F$ values of the post midnight hours, over the same station, Fortaleza. Thus, the observation of the PW/UFK wave oscillations in the F layer height during post sunset-pre midnight hours reported in the literature (for example, Takahashi et al. 2007, 2009; Fagundes et al. 2009) are indeed indicative of the manifestations of the PRE modulation by the upward propagating waves. We may further call attention to the fact that in a study using NCAR GCM simulation, Chang et al. (2010) obtained TEC oscillations of $25 \%$ to $50 \%$ due to an upward propagating UFK wave when their calculations included electrodynamic coupling. The amplitudes of the oscillations were significantly stronger during 20- to 24-LT interval than when either the daytime mean or nighttime mean value was considered. This appears to suggest the UFK effect on PRE impacting the post sunset TEC values.

\section{Conclusions}

In this work, we undertook to characterize the global nature of the eastward propagating Kelvin waves in the MLT region and to understand the upward propagation characteristics of the waves involving vertical coupling through neutral dynamics extending from the stratosphere to the MLT region and further to the ionospheric F region involving electrodynamic coupling processes. Mesospheric winds (zonal and meridional components) from equatorial and low-latitude radars from Brazil and India, SABER temperature in the height region of 40 to $120 \mathrm{~km}$, and $\mathrm{F}$ region vertical drift measured by Digisonde in Brazil were used in the analysis. The period of investigation was in general marked by FK and UFK wave activities, the FK waves dominating the lower height and being subject to wave amplification until approximately $100 \mathrm{~km}$ (as seen in the SABER temperature). From simultaneous observations of the MLT winds over Brazilian and Indian longitudes, the eastward phase velocities of the FK and UFK waves, being approximately 100 and $120 \mathrm{~km}$, respectively, were found to be compatible with their values published in previous studies. Extensive focus in this work was on the upward propagation characteristics of the waves into the MLT region followed by the electrodynamic coupling to F region heights resulting in strong modulation of the prereversal vertical plasma drift and consequent effects in the post sunset equatorial spread $\mathrm{F}$ bubble irregularity development. For the first time, it is observed that both the FK and UFK waves can cause the PRE vertical drift oscillations. The FK wave activity showed upward propagation characteristics marked by wave amplification and delayed occurrence with increasing height, suggesting an upward propagation speed of approximately $4 \mathrm{~km} /$ day (as revealed by the SABER temperature data between approximately 40 and $100 \mathrm{~km}$ ). This was in close agreement with such vertical propagation speed observed previously also using SABER data. There is also a clear delay (by around 10 days) between the occurrence of the FK and UFK wave oscillations in the MLT region and their manifestation in the form of corresponding oscillation in $\mathrm{F}$ region vertical drift. It is found that the observed upward propagation speed of FK/UFK waves is not compatible (being too slow) with these waves propagating up to $\mathrm{F}$ region heights to produce the modulation in the PRE vertical drift by local interactive processes but was compatible with these waves reaching only up to the dynamo region that is electrically coupled 
to the F layer heights of the PRE manifestation. This leads us to the conclusion that the FK/UFK wave modulation of the E layer winds should be responsible for the oscillations in the PRE vertical drift velocity, which is also in good agreement with the results from our previous investigations (Abdu et al. 2006b). The mechanism connecting the E region zonal wind oscillations with PRE vertical drift appears to be through the zonal wind modulation of the evening E layer conductivity local time/longitude gradient (also based on our previous work). The FK/UFK-induced oscillations in the vertical drift causes strong modulation in the intensity and onset time of the post sunset spread F irregularity development. The UFK wave oscillations observed in August 2005 do not seem to be sufficient to trigger ESF/plasma bubble development in this month, which is a season of spread F nonoccurrence over Brazil. The FK/UFK waves are thus an important cause of the widely observed day-to-day variability in the equatorial $\mathrm{F}$ region vertical drift and plasma bubble development during the season of SF occurrence. Our results do not support the need for the waves to propagate to the $\mathrm{F}$ region height in order to cause the observed variabilities in PRE and ESF. However, further work will be useful to establish the vertical propagation characteristics and upward group velocity of the FK/UFK waves.

\section{Competing interests}

The authors declare that they have no competing interests.

\begin{abstract}
Authors' contributions
MAA conceived and coordinated this study, analyzed the Digisonde data, interpreted the results, and wrote the first draft of the paper. CGMB analyzed part of the data. PPB provided the meteor wind data partially analyzed. SG contributed MF radar wind data. DP analyzed and partially interpreted the SABER temperature data. JVB contributed in the analysis of related SABER temperature data. ISB contributed in Digisonde data collection. HT participated in data interpretation. All authors read and approved the final manuscript.
\end{abstract}

\begin{abstract}
Acknowledgements
This work was supported by the Conselho Nacional de Desenvolvimento Científico e Tecnológico (CNPq) through the process CNPq no. 300883/2008-0. The Arecibo Observatory is operated by SRI International under a cooperative agreement with the NSF (AST-1100968) and in alliance with Ana G. MéndezUniversidad Metropolitana and the Universities Space Research Association. This work is the result of a collaboration effort within the CAWSES II TG4 project.
\end{abstract}

\section{Author details \\ 'Instituto Nacional de Pesquisas Espaciais (INPE), Sao Jose dos Campos 12227-010, Brazil. ${ }^{2}$ National Astronomy and lonosphere Center, Space and Atmospheric Sciences Department, Arecibo Observatory, SRI International, Arecibo 00612, Puerto Rico. Indian Institute of Geomagnetism, Navi Mumbai 410 218, India. ${ }^{4}$ Geophysical Institute, Bulgarian Academy of Sciences, Sofia 1040, Bulgaria.}

Received: 29 April 2014 Accepted: 14 October 2014

Published online: 06 January 2015

\section{References}

Abdu MA, Brum CGM (2009) Electrodynamics of the vertical coupling processes in the atmosphere-ionosphere system of the low latitude region. Earth Planets Space 61:385-395
Abdu MA, Batista I, Sobral JHA (1992) A new aspect of magnetic declination control on equatorial spread F and F region dynamo. J Geophys Res 97(10):14897-14904

Abdu MA, MacDougall JW, Batista IS, Sobral JHA, Jayachandran PT (2003) Equatorial evening prereversal electric field enhancement and sporadic $E$ layer disruption: a manifestation of E and F region coupling. I Geophys Res 108(A6):1254, doi:10.1029/2002JA009285

Abdu MA, Batista IS, Reinisch Bodo W, Carrasco AJ (2004) Equatorial F-layer height, evening prereversal electric field, and night $E$ layer density in the American sector: IRI validation with observations. Adv Space Res 34:1953-1965, London

Abdu MA, Ram Kumar TK, Batista IS, Brum CGM, Takahashi H, Reinisch BW, Sobral JHA (2006a) Planetary wave signatures in the equatorial atmosphereionosphere system, and mesospheire - $\mathrm{E}$ - and $\mathrm{F}$ region coupling. J Atmospheric Solar-Terrestrial Physics 68:509-522

Abdu MA, Batista PP, Batista IS, Brum CGM, Carrasco A, Reinisch BW (2006b) Planetary wave oscillations in mesospheric winds, equatorial evening prereversal electric field and spread F. Geophys Res Lett 33(L07107):1-4

Abdu MA, Kherani EA, Batista IS, Sobral JHA (2009) Equatorial evening prereversal vertical drift and spread $\mathrm{F}$ suppression by disturbance penetration electric fields. Geophys Res Lett 36, L19103, doi:10.1029/2009GL039919

Abdu MA, Batista IS, Reinisch BW, MacDougall JW, Kherani EA, Sobral JHA (2012) Equatorial range spread $\mathrm{F}$ echoes from coherent backscatter, and irregularity growth processes, from conjugate point digital ionograms. Radio Sci 47, RS6003, doi:10.1029/2012RS005002

Batista IS, Abdu MA, Bittencourt JA (1986) Equatorial F-region vertical plasma drifts: seasonal and longitudinal asymmetries in the American sector. J Geophys Res 91:12055-12064

Bilitza D, Reinisch BW (2008) International Reference lonosphere 2007: improvements and new parameters. Adv Space Res 42:599-609, doi:10.1016/j.asr.2007.07.048

Chang LC, Palo SE, Liu H-L, Fang T-W, Lin CS (2010) Response of the thermosphere and ionosphere to an ultra fast Kelvin wave. J Geophys Res 115:A00G04. doi:10.1029/2010JA015453

Chang LC, Liu JY, Palo SE (2011) Propagating planetary wave coupling in SABER MLT temperatures and GPS TEC during the 2005/2006 austral summer. J Geophys Res 116, A10324, doi:10.1029/2011JA016687

Chen PR (1992) Two-day oscillations of the equatorial ionization anomaly. J Geophys Res 979(A5):6343-6357

Chen Y-W, Miyahara S (2012) Analysis of fast and ultrafast Kelvin waves simulated by the Kyushu-GCM. Atmos Solar-Terrest Phys 80:1-11

Davis RN, Chen Y-W, Miyahara S, Mitchell NJ (2012) The climatology, propagation and excitation of ultra-fast Kelvin waves as observed by meteor radar, Aura MLS, TRMM and in the Kyushu-GCM. Atmos Chem Phys 12:1865-1879, doi:10.5194/acp-12-1865-2012

Eccles JV (1998) A simple model of low-latitude electric fields. J Geophys Res 103:26699-26708

Fagundes PR, Abalde JR, Bittencourt JA, Sahai Y, Francisco RG, Pillat VG, Lima WLC (2009) F layer postsunset height rise due to electric field prereversal enhancement: 2. Traveling planetary wave ionospheric disturbances and their role on the generation of equatorial spread F. J Geophys Res 114, A12322, doi:10.1029/2009JA014482

Farley DT, Bonelli E, Fejer BG, Larsen MF (1986) The prereversal enhancement of the zonal electric field in the equatorial ionosphere. J Geophys Res 91:13723-13728

Fejer BG, Jensen JW, Su S-Y (2008) Seasonal and longitudinal dependence of equatorial disturbance vertical plasma drifts. Geophys Res Lett 35, L20106, doi:10.1029/2008GL035584

Forbes JM (2000) Wave coupling between the lower and upper atmosphere: case study of an ultra-fast Kelvin wave. J Atmos Sol Terr Phys 62:1603-1621

Forbes JM, Leveroni S (1992) Quasi 16-day oscillations in the ionosphere. Geophys Res Lett 19:981-984

Gurubaran S, Sridharan S, Ram Kumar TK, Rajaram R (2001) The mesospheric quasi 2-day wave over Tirunelveli. J Atmos Terr Phys 63:975-985

Haerendel G, Eccles JV (1992) The role of the equatorial electrojet in the evening ionosphere. J Geophys Res 97:1224-1243

Haldoupis C, Pancheva D, Mitchell NJ (2004) A study of tidal and planetary wave periodicities present in midlatitude sporadic E layers. J Geophys Res 109, A02302, doi:10.1029/2003JA010253

Harris TJ (1994) A long-term study of the quasi-two-day wave in the middle atmosphere. J Atmos Terr Phys 56:569-579 
Heelis RA, Kendall PC, Moffet RJ, Windle DW, Rishbeth H (1974) Electrical coupling of the $\mathrm{E}$ - and F-region and its effects on the $\mathrm{F}$ region drifts and winds. Planet Space Sci 22:743-756

Hirota I (1978) Equatorial waves in the upper stratosphere and mesosphere in relation to the semiannual oscillation of the zonal wind. J Atmos Sci 35:714-722

Hocking WK, Fuller B, Vandepeer B (2001) Real-time determination of meteor-related parameters utilizing modern digital technology. J Atmos Sol Terr Phys 63(2-3):155-169

Kikuchi T, Hashimoto KK, Nozaki K (2008) Penetration of magnetospheric electric fields to the equator during a geomagnetic storm. J Geophys Res 113, A06214, doi:10.1029/2007JA012628

Kovalam S, Vincent RA, Reid IM, Tsuda T, Ohnishi K, Nuryanto A, Wiryosumarto H (1999) Longitudinal variations in planetary wave activity in the equatorial mesosphere. Earth Planets Space 51:665-674

Lima LM, Batista PP, Takahashi H, Clemesha BR (2004) Quasi-two-day wave observed by meteor radar at $22.7^{\circ} \mathrm{S}$. J Atmos Solar-Terr Phys V66(6-9):529-537

Lima LM, Medeiros AF, De Buriti RA, Batista PP, Clemesha BR, Takahashi H (2007) Mesospheric 2-day waves observed simultaneously in the equatorial and low latitude regions of Brazil. Revista Brasileira de Geofísica 25(Supl. 2):43-48

Lima LM, de Oliveira AE, Medeiros AF, Buriti RA, Batista PP, Clemesha BR, Takahashi H (2008) 3-4 day Kelvin waves observed in the MLT region at 7.4 S, Brazil. Geofísica Internacional V47(3):153-160

Liu G, Immel TJ, England SL, Frey HU, Mende SB, Kuma KK (2013) Impacts of atmospheric ultrafast Kelvin waves on radio scintillations in the equatorial ionosphere. J Geophys Res Space Physics 118:885-891. doi:10.1002/jgra.50139

Miyoshi Y, Fujiwara H (2006) Excitation mechanism of intraseasonal oscillation in the equatorial mesosphere and lower thermosphere. J Geophys Res 111, D14108, doi:10.1029/2005JD006993

Onohara AN, Batista IS, Takahashi H (2013) The ultra-fast Kelvin waves in the equatorial ionosphere: observations and modeling. Ann Geophys 31:209-215

Pancheva D, Haldoupis C, Meek CE, Manson AH, Mitchell NJ (2003) Evidence of a role for modulated atmospheric tides in the dependence of sporadic $E$ layers on planetary waves. J Geophys Res 108(A5):1176

Pancheva D, Mitchell NJ, Younger PT (2004) Meteor radar observations of atmospheric waves in the equatorial mesosphere/lower thermosphere over Ascension Island. Ann Geophys 22:387-404

Pancheva D, Mukhtarov P, Andonov B, Mitchell NJ, Forbes JM (2009) Planetary waves observed by TIMED/SABER in coupling the stratosphere-mesospherelower thermosphere during the winter of 2003/2004: part 1-comparison with the UKMO temperature results. J Atmos Sol-Terr Phys 71:61-74

Pancheva D, Mukhtarov P, Andonov B, Forbes JM (2010) Global distribution and climatological features of the 5-6-day planetary waves seen in the SABER/ TIMED temperatures (2002-2007). J Atmos Sol-Terr Phys 72:26-37

Riggin D, Fritts DC, Tsuda T, Nakamura T, Vincent RA (1997) Radar observations of a 3-day Kelvin wave in the equatorial mesosphere. J Geophys Res 102:26141-26157

Rishbeth H (1971) Polarization fields produced by winds in the equatorial $F$ region. Planet Space Sci 19:357-369

Salby ML, Hartmann DL, Bailey PL, Gille JC (1984) Evidence for equatorial Kelvin modes in Nimbus-7 LIMS. J Atmos Sci 41:220-235

Sridharan S, Gurubaran S, Rajaram R (2002) Radar observations of the 3.5-day ultra-fast Kelvin wave in the low-latitude mesosphere region. J Atmos Sol-Terr Phys 64:1241-1250

Takahashi H, Lima LM, Wrasse CM, Abdu MA, Batista IS, Gobbi D, Buriti RA Batista PP (2005) Evidence on 2-4 day oscillations of the equatorial ionosphere h'F and mesospheric airglow emission. Geophys Res Lett 32, L12102, doi:10.1029/2004GL022318

Takahashi H, Wrasse CM, Pancheva D, Abdu MA, Batista IS, Lima LM, Batista PP, Clemesha BR, Shiokawa K (2006) Signatures of 3-6 day planetary waves in the equatorial mesosphere and ionosphere. Ann Geophys 24:3343-3350

Takahashi H, Wrasse CM, Fechine J, Pancheva D, Abdu MA, Batista IS, Lima LM, Batista PP, Clemesha BR, Schuch NJ, Shiokawa K, Gobbi D, Mlynczak MG, Russel JM (2007) Signature of ultra fast Kelvin waves in the equatorial middle atmosphere and ionosphere. Geophys Res Lett 34:L1108-1

Takahashi H, Abdu MA, Wrasse CM, Fechine J, Batista IS, Pancheva D, Lima LM, Batista PP, Clemesha BR, Shiokawa K, Gobbi D, Mlynczak MG, Russel JM (2009) Possible influence of ultra-fast Kelvin wave on the equatorial ionosphere evening uplifting. Earth Planets Space 61:455-462

Uma J, Liu Y, Chen SP, Sun YY, Brahmanandam PS, Lin CH (2012) A comparison of the equatorial spread $F$ derived by the International Reference lonosphere and the $S_{4}$ index observed by FORMOSAT-3/COSMIC during the solar minimum period of 2007-2009. Earth Planets Space 64(6):467-471

Vincent RA (1993) Low frequency dynamics of the equatorial mesosphere. In: Trane EV, Blix TA, Fritts DC (eds) Coupling processes in the lower and middle atmosphere. Kluwer, Netherlands, pp 125-136

Vincent RA, Lesicar D (1991) Dynamics of the equatorial mesosphere: first results with a new generation partial reflection radar. Geophys Res Lett 18:825-828

\section{Submit your manuscript to a SpringerOpen ${ }^{\odot}$ journal and benefit from:}

- Convenient online submission

- Rigorous peer review

- Immediate publication on acceptance

- Open access: articles freely available online

- High visibility within the field

- Retaining the copyright to your article

Submit your next manuscript at $>$ springeropen.com 